NASA Technical Memorandum 105610

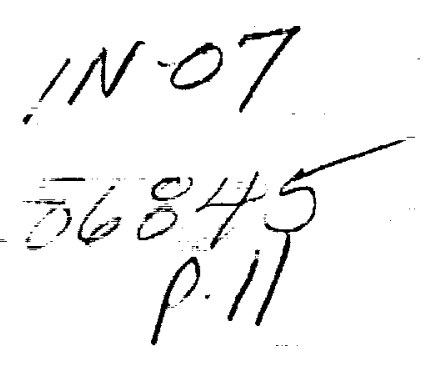

\title{
Effects of Turbine Cooling Assumptions on Performance and Sizing of High-Speed Civil Transport
}

Paul F. Senick

Lewis Research Center

Cleveland, Ohio

May 1992

\section{N/SN}

(NASA-TM-105610) EFFECTS OF TURBINE CODLING ASSUMPTIONS ON PERFORMANCE AND SIZING OF HIGH-SPEED CIVIL TRANSPORT (NASA) $11 \mathrm{p}$ 


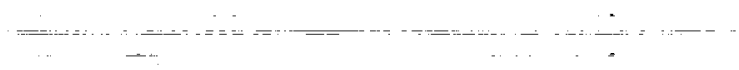$$
\text { - }
$$

$=$

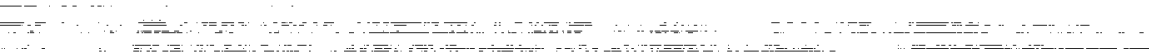




\title{
EFFECTS OF TURBINE COOLING ASSUMPTIONS ON PERFORMANCE AND
}

\section{SIZING OF HIGH-SPEED CIVIL TRANSPORT}

\author{
Paul F. Senick \\ National Aeronautics and Space Administration \\ Lewis Research Center \\ Cleveland, Ohio 44135
}

\section{SUMMARY}

The analytical study presented herein examines the effects of varying turbine cooling assumptions on the performance of a High-Speed Civil Transport propulsion system as well as the sizing sensitivity of this aircraft to these performance variations. The propulsion concept employed in this study was a twospool, variable-cycle engine with a sea-level thrust of $55000 \mathrm{lbf}$. It is one of several promising cycles being considered to power the High-Speed Civil Transport within the High-Speed Research Program. The aircraft used for this study was a representative 250-passenger vehicle with a cruise Mach number of 2.4 and a 5000-n mi range. The differences in turbine cooling assumptions were represented by varying the amount of high-pressure compressor bleed air (2 percent for fuel-cooled or ceramic turbines to 24 percent for current turbine materials) used to cool the turbines. It was found that as this cooling amount was increased, the engine size and weight increased but specific fuel consumption (at takeoff and climb) decreased. However, all study engines had approximately the same cruise value of specific fuel consumption. Because most of the mission is spent at cruise, the specific fuel consumption advantage of the higher bleed engines seen during subsonic flight was minimized and the lower bleed, lighter weight engines led to the lowest takeoff-gross-weight vehicles. Finally, the change in aircraft takeoff gross weight versus turbine cooling level is presented.

\section{INTRODUCTION}

The desire for higher flight speeds and shorter travel times has been and continues to be a strong driver in the design of future aircraft. Recent advancements in propulsion technologies as well as those predicted for the next 15 years indicate a high probability that an economically viable, environmentally acceptable High-Speed Civil Transport (HSCT) vehicle may become a reality. There are many challenges to the design of such an aircraft, but the accepted opinion is that the most crucial challenges lie in the propulsion system that will power the HSCT. The most difficult propulsion issues are noise, ozonedepleting $\mathrm{NO}_{\mathrm{x}}$ emissions, material limitations, and fuel consumption. The economic viability of an HSCT in the years 2005 to 2015 is greatly dependent on the favorable resolution of these engine challenges (ref. 1). In 1987, preliminary studies began that would support the High-Speed Research (HSR) Program initiated in 1990 to examine and develop the key technologies that would make an HSCT an economical and technological reality.

The demand for an economically acceptable HSCT over a long-range mission (5000 to $6500 \mathrm{n} \mathrm{mi}$ ) requires the use of an engine that can not only comply with Federal Aviation Regulations (FAR) 36 Stage 3 noise rules at takeoff, but also cruise supersonically at Mach numbers between 1.6 and 2.4. Although the HSCT is being considered for initial operational capability in the early 2 Ist century, combustor exit temperatures of $3500^{\circ} \mathrm{R}$ and higher will put serious demands on the design of the turbine or turbines of such an engine. Because the HSCT operates its engines at the maximum allowable combustion temperature for the majority of its mission, the turbines will have to withstand this extreme heat for prolonged periods. The turbine blades will be highly susceptible to creep rather than the cyclic fatigue that is experienced by subsonic transports whose maximum combustion temperature only occurs at takeoff and during climb and for supersonic military aircraft that operate at speeds greater than 
Mach 1 for short periods of time. Turbine cooling requirements may be pushed to the point where they seriously constrain the performance of the engine unless advances in turbine materials and turbine blade cooling methods are aggressively pursued and realized.

Over the last 3 years turbine material assumptions for an HSCT propulsion system have varied within the program. The turbine blades must withstand the greatest thermodynamic and structural loads of any turbine component and therefore receive most of the cooling air ported from the high-pressure compressor. Although it is generally believed the turbine blades will be fabricated from an advanced nickel alloy, estimation of the materials' capability and cooling needs in an HSCT engine application has varied.

The objective of this study was not to substantiate or deny any of the HSR program material assumptions, but simply to show how these varying assumptions influence the engine's design and performance as well as the sizing of the HSCT vehicle it powers. For predictions regarding current and future materials' capabilities consult references 2 to 4 .

\section{ENGINE DESIGN METHOD}

The propulsion concept used for this study was a two-spool, variable-cycle engine (VCE). The VCE is currently being studied within NASA Lewis Research Center and at General Electric Company for use on the High-Speed Civil Transport of the HSR program. The engine cycle used herein conforms to the HSR propulsion system groundrules determined by General Electric Company and United Technologies/Pratt \& Whitney as of December 1991. The groundrules consist of structural and thermodynamic limits as well as noise and emission goals. The VCE has been studied thoroughly by industry and NASA Lewis since the NASA-sponsored Supersonic Transport and Supersonic Cruise Research programs that began in the 1970's and concluded in 1981. A VCE was a recent candidate to power the United States Air Force Advanced Tactical Fighter.

The flowpath of the VCE is shown in figure 1, and some of the more critical design values employed in this investigation are listed in table $\mathrm{I}$. This concept is a derivative cycle of a conventional two-spool turbofan, with three important exceptions. The first and foremost one can be seen in figure 1. The VCE has two bypass ducts instead of the turbofan's one. The outer, or secondary, bypass duct is used as a valve that can be opened and closed at the designer's discretion. The VCE operates like a turbofan at takeoff and during most of climb $(M<1.6)$ with the outer bypass duct closed. At higher Mach numbers, during cruise, and during part-power operation, the outer bypass duct is opened, effectively increasing the overall bypass of the engine. The second exception is the presence of a coredriven fan (CDF) placed directly in front of the high-pressure compressor (HPC), which gives a boost in pressure (usually no more than $\mathbf{4 0}$ percent) to the core and bypass flows. The third exception is the placement of the primary (inner) bypass duct. As shown in figure 1, it is placed after the CDF instead of behind the front fan as in a conventional turbofan. The presence of the CDF and the placement of the primary bypass duct (following it) provides a nearly constant bypass ratio for the VCE at all flight conditions because the front fan is allowed to pass only as much air as the CDF can handle.

All engine models used herein and their corresponding installed cycle performances were generated by using the NASA Lewis Engine Performance Program (NEPP) (ref. 5). The baseline VCE used in this study represented the author's "best" engine to date leading to the lowest takeoff-gross-weight (TOGW) vehicle. For all study engines HPC cooling air was divided between the high-pressure turbine (HPT) and the low-pressure turbine (LPT) in a $\mathbf{8 7 . 5}$ percent/12.5 percent split, respectively, as is consistent with the HSCT groundrules. NEPP performs a mass-weighted enthalpy balance between the core flow and the 
cooling flow entering the turbine. The cooling flow enters a turbine at the designer's chosen location (or locations). For this study the cooling flow entering a turbine was split, sending half of it in front of that turbine and the rest behind it. This was done to simulate the real energy losses that would occur in the engine from the turbine cooling process. Work is derived from the flow that is ported in front of a given turbine. No work is derived from the cooling flow that is ported behind the turbine. Pressure losses due to the ducting of this cooling air were not accounted for. All study engines were initially scaled to create $55000 \mathrm{lbf}$ of maximum dry thrust for a sea-level static takeoff. This was done for performance comparison purposes only and does not reflect any design strategy whatsoever.

All study engines were designed at Mach 2.4 (at $60000 \mathrm{ft}$ ) with the engine parameters listed in table I. Fan pressure ratios were chosen such that the pressure ratio of bypass ducted air to LPT exit air (at design) was 1.3. This ratio is referred to as $k$ in the remainder of the report. It was found that this ratio had a strong influence on mixing and overall performance. Lower values of $k$ resulted in decreased engine performance; higher $k$ 's normally resulted in the flow becoming sonic in the secondary side of the mixer. For off-design operation of this engine $k$ was optimized to maximize thrust. The HPC pressure ratios were chosen such that the maximum total temperature at the compressor exit matched the HSR program groundrules.

The baseline engine cycle used $\mathbf{1 7 . 5}$ percent bleed air from the HPC to cool the high-pressure and low-pressure turbines. This number was derived from turbine material cooling needs for existing engines as well as predictions for materials expected to be available for use in the HSR program. Three other values of cooling bleed were investigated to illustrate the engine performance changes and the consequences of these changes on the TOGW of the HSCT from those of the baseline engine. The next section of this report addresses the design differences of the four study engines as well as their performance variations caused by these differences.

It should be stressed that this design philosophy was a first-order attempt to reoptimize the VCE cycle to account for the varying turbine cooling flows of the study. If a fixed-design engine were forced to operate with these four cooling percentages, the performance changes shown in the next section would have been much more pronounced. A simple comparison was conducted by taking the 2-percent cooling bleed engine and running it with 24-percent cooling. The thrust performance in that case was about half that for the "optimized" 2- and 24-percent HPC cooling bleed engines shown in this report.

\section{STUDY-ENGINE DESIGN DIFFERENCES AND PERFORMANCE}

The effects of four turbine cooling technologies were studied by varying the amount of air bled from the HPC (and ported to the turbines) of the baseline study engine. Design variations of these engines will be discussed shortly. The baseline engine represented the author's current "best" engine (leading to the lowest TOGW vehicle) and required 17.5-percent bleed air from the HPC to cool the high- and lowpressure turbines. The three other HPC cooling bleeds investigated were 2,10 , and 24 percent. The 2 -percent value was chosen to represent an absolute lower bound (where 2 percent of HPC air is assumed lost through leakage). Although this lower bound may be achievable by using fuel-cooled or ceramic (uncooled) turbine blades, the technology required to reach this goal will most likely not be mature enough to employ within the HSR program timeframe. A value of 10 -percent HPC bleed was chosen as an intermediate estimate for turbine cooling, perhaps representing a combination of advances in turbine blade material and cooling methods. This value, however, is also regarded as a significant technical risk and unachievable within the HSR program timetable. The general trend for turbine cooling assumptions within the HSR program has pointed continually toward an ever-increasing need for cooling air. The 
24-percent HPC bleed configuration represented a chosen upper bound above which engine thrust performance was found to be significantly reduced.

The major engine design parameters at takeoff (sea-level static) and at Mach 2.4 at $60000 \mathrm{ft}$ (maximum dry) are listed in table I. Some expected trends are immediately evident. The total physical airflow $W_{a}$ of the engines increased as the HPC cooling bleed air was increased. The highly compressed air that was bled off the HPC and used for cooling bypassed the core (with only a small momentum benefit regained by the core flow when it was reintroduced at the turbines for cooling). In effect, this cooling air increased the overall bypass of the engine. The characteristic thermodynamic and performance trends of the VCE differed little from those of a mixed-flow turbofan. Thus, as overall bypass air increased (cooling air in this case), installed thrust $F_{n}$, specific thrust $F_{n} / W_{a}$, and specific fuel consumption (SFC) decreased. This behavior is shown in table $I$ and in figures 2 to 4 . Because a requirement in this study was for all engines to produce 55 000-lbf thrust at takeoff, engine airflow (which scales directly with thrust) increased as HPC cooling bleed amounts increased. The ramifications of these trends will become readily apparent when the engine weights and mission analysis are discussed.

Also shown in table I are decreasing fan pressure ratios and increasing HPC pressure ratios with increasing HPC cooling flows. As previously mentioned, all study engines were designed at a match point of Mach 2.4 at $60000 \mathrm{ft}$ at the maximum allowable combustor temperature, the HPC exit temperature $T_{3}$, and a $k$ of 1.3. The effects of these design features are as follows: In order to attain the maximum allowable $T_{3}$ while keeping the combustor temperature constant, the pressure ratio of the HPC must increase as the amount of air bled off it (for turbine cooling) increases. The reason is that increasing the amount of HPC cooling bleed decreases the amount of air that can be heated and used by the turbines to do work (although some of the energy and momentum from the compressed cooling air is recouped when it is ported into the turbines for cooling). Because all engines were designed at the same combustor temperature yet required approximately the same amount of work to turn the compressor and the fans, more energy was extracted from the core flow than with lesser cooling amounts. As this additional energy was drawn from the core flow, the total pressure of the core flow decreased correspondingly. When the air reached the mixer, the ratio of $k$ desired was 1.3. To achieve this value and because the total pressure of the core flow decreased with increasing HPC cooling bleed, the total pressure of the bypass air had to be reduced by decreasing the fan pressure ratio of the given study engine. The ramifications of these design changes to the HSCT TOGW are not immediately apparent here but will become clear when the engine weights are considered.

\section{ENGINE WEIGHTS}

The geometry and weights of the study engine components and the overall bare engine weights (inlet and nozzle weights calculated separately) were determined by using an engine weight estimation computer code called WATE-2 (Weight Analysis of Turbine Engines, ref. 6). The methods used to determine inlet and nozzle weights for the study engines will be discussed shortly. WATE-2 requires the thermodynamic cycle outputs of the NEPP code as well as user-supplied material and structural inputs. The engine material and structural assumptions used in this study were consistent with the HSR program groundrules.

The inlet weights were calculated by using IPSSO (ref. 7), an inlet weight estimation code, which requires the geometry and pressure profile of the engine inlet and the inlet diameter as calculated by WATE-2 (fan diameter). Mixer-ejector nozzles were assumed for this study and are currently the most promising for the HSCT in terms of suppressing jet noise. The mixer-ejector nozzle weights used here were based on a first-order correlation between the total engine airflow, the ideal primary jet velocity, 
and the mixer ejector flow that is needed to suppress engine noise and meet HSR program goals. As ideal jet velocity increases, so too does jet noise. The correlation therefore assumes that as jet velocity increases, the amount of air taken aboard by the nozzle must be increased to suppress the noise associated with it. As this amount of air increases, the nozzle itself becomes larger and heavier to handle this increased flow. This correlation was taken from reference 8.

It was shown that in order to achieve the desired takeoff thrust of $55000 \mathrm{lbf}$, total engine airflow increased with increasing HPC cooling bleeds. Engine component weights correspondingly increased. The total engine pod weights shown in table II exhibit this trend. The 20-percent increase in pod weight from the 2- to the 24-percent HPC bleed was due primarily to the effective increase in engine bypass that the cooling air represents. As with any turbofan engine, as the bypass of the engine is increased and the design thrust is held constant, the engine airflow must grow to make up for the thrust loss by bypassing more air. Thus, the engine weight grows with bypass or, in this case, cooling air. Study engines with higher cooling flows had lower jet velocities just as turbofans with higher bypass ratios have. From the reference 8 nozzle weight correlation, lower jet velocity engines need less noise suppression and also have lower specific weight nozzles. Although the higher cooling bleed engines weighed more overall, their corresponding nozzles weighed less per unit airflow than did the lower bleed cases.

The increase in propulsion pod weight shown in table II would imply that weight gains will be necessary on the aircraft on which these engines are flown.

\section{MISSION PERFORMANCE}

The study aircraft chosen was a representative four-engine, 250-passenger HSCT with a cruise speed of Mach 2.4 (at approx. $60000 \mathrm{ft}$ ) and a 5000-n mi range. The mission consisted of a takeoff, a climb leg, a supersonic cruise leg, a reserve, and a descent. Mission analysis was done by using the Aircraft Sizing Program (ASP) (ref. 9). ASP assumes the best available Breguet cruise factor when flying a mission. The propulsion system weights and their corresponding performance were incorporated into the ASP mission deck and flown separately through a TOGW contour matrix of thrust loadings versus wing loadings to determine the lowest TOGW HSCT for each study engine. The initial propulsion system size was varied by the thrust loading, and the wing size by the wing loading inputs, given to the ASP code. Aircraft weights and aerodynamics are correspondingly altered by ASP according to accepted methods applicable to high-speed transport aircraft. Constraints of takeoff field length (11 $000 \mathrm{ft})$, no excess fuel storage, and a climb time of $\mathbf{4 5}$ min were applied to each TOGW contour. An example of one of these matrices or "thumbprints" is shown in figure 5 for the baseline 17.5-percent HPC bleed engine. The approximate optimum-TOGW aircraft powered by this engine is marked on the plot.

The lowest TOGW aircraft was thus determined (within the stated constraints) for each study propulsion system. In figure 6 the mission analysis results are shown. The magnitude of change from the baseline to any of the study engines was not greater than 4 percent. The primary reason for this is that each engine had been optimized for a given HPC cooling bleed. Although the lower bleed engines had slightly better thrust characteristics and were lighter engines, they had higher SFC's and consumed more fuel per pound of engine weight (during takeoff and climb) than did the higher bleed engines. These trends tended to offset one another so that the end result was that TOGW did not change as significantly as it might have. The SFC advantage of the higher bleed engines (during takeoff and climb) were not realized fully, however, because most of the HSCT's mission is spent at cruise. Figure 4 shows that there was very little difference in SFC at cruise between study engines and therefore the engine weight trend discussed earlier dominated the aircraft sizing differences. 
The TOGW changes that occurred from the 2-percent cooling bleed engine to the 24-percent bleed engine were as follows: Forty-two percent of the weight difference was due to fuel usage, 32 percent was due to propulsion system weight change, and about 26 percent came from the aircraft structure and systems.

\section{CONCLUSIONS}

The results of a study of the effects of turbine cooling assumptions on the engine performance and takeoff gross weight (TOGW) of a High-Speed Civil Transport (HSCT) were presented herein. Four engines with varying amounts of high-pressure compressor cooling bleed (ported to the turbines) were used in the study. From the 2-percent cooling bleed engine to the 24-percent case, the TOGW of the HSCT varied by 8 percent. Although the higher bleed engines had better takeoff and climb specific fuel consumptions, they showed little or no improvement at cruise and were heavier. In fact, the majority of the 8-percent TOGW variation was due to the change in engine weight.

It should be reiterated that fan pressure ratio and high-pressure-compressor pressure ratio were not fixed for this study. They were adjusted so that cycle performance could be optimized depending on how much cooling flow was assumed for the engine's turbines. The changes in engine performance and TOGW from the 2-percent cooling bleed engine to the 24-percent case may have been greatly exaggerated had this not been done.

The conclusions of this study show the importance of cycle optimization in alleviating engine performance losses due to turbine cooling assumptions and the effect that turbine material and cooling technologies actually have on an engine cycle as applied to an HSCT mission.

\section{REFERENCES}

1. High-Speed Civil Transport Study. NASA CR-4233, 1989.

2. Hughes, J.W.: Benefits of Advanced Materials and Structures in a Mach 2.4 HSCT Turbine Bypass Engine. HITEMP Review 1991: Advanced High Temperature Engine Materials Technology Program, 1991, NASA CP-10082, p. 14.

3. Allen, G.E., et al.: Benefits of Advanced Materials in Future High Speed Civil Transport Propulsion Systems. NASA CR-185246, 1990.

4. HITEMP Review 1991: Advanced High Temperature Engine Materials Technology Program, NASA CP-10082, 1991.

5. Plencner, R.M., and Snyder, C.A.: The Navy/NASA Engine Program (NNEP89) - A Users Manual. NASA TM-105186, 1991.

6. Onat, E. and Klees, G.W.: A Method to Estimate Weight and Dimensions of Large and Small Gas Turbine Engines. NASA CR-159481, 1979.

7. Moses, P, and Jones, C.: Internally Pressurized Structural Synthesis and Optimization Code. Internal Report. NASA Langley Research Center, 1987. 
8. Seidel, J.A., Haller, W.J., and Berton, J.J.: Comparison of Turbine Bypass and Mixed Flow Turbofan Engines for a High-Speed Civil Transport. AIAA Paper 91-3132, 1991.

9. Fetterman, D.E., Jr.: Preliminary Sizing and Performance of Aircraft. NASA TM-86357, 1985.

TABLE I. - DESIGN VARIATIONS OF STUDY ENGINES

(a) Sea-level static takeoff (55 000-lbf) thrust

\begin{tabular}{|c|c|c|c|c|}
\hline \multirow[t]{2}{*}{ Design parameter } & \multicolumn{4}{|c|}{$\begin{array}{l}\text { High-pressure-compressor bleed, } \\
\text { percent }\end{array}$} \\
\hline & 2 & 10 & 17.5 & 24 \\
\hline Airflow, $W_{a}, \mathrm{lbm} / \mathrm{sec}$ & 633 & 674 & 717 & 764 \\
\hline Fan pressure ratio & 3.95 & 3.58 & 3.23 & 2.92 \\
\hline $\begin{array}{l}\text { Core-driven-fan } \\
\text { pressure ratio }\end{array}$ & 1.36 & 1.38 & 1.40 & 1.40 \\
\hline $\begin{array}{l}\text { High-pressure- } \\
\text { compressor } \\
\text { pressure ratio }\end{array}$ & 4.11 & 4.46 & 4.88 & 5.34 \\
\hline $\begin{array}{l}\text { Overall pressure } \\
\text { ratio }\end{array}$ & 22 & 22 & 22 & 22 \\
\hline Bypass ratio: & & & & \\
\hline Inner & 0.67 & 0.67 & $\begin{array}{r}0.67 \\
0\end{array}$ & $\begin{array}{r}0.67 \\
0\end{array}$ \\
\hline $\begin{array}{l}\text { Combustor exit } \\
\text { temperature, }{ }^{\circ} \mathrm{R}\end{array}$ & 3368 & 3361 & 3356 & 3352 \\
\hline $\begin{array}{l}\text { Ratio of thrust to } \\
\text { airflow, } F_{n} / W_{a} \\
\text { lbf-sec/lbm }\end{array}$ & 86.6 & 81.7 & 76.7 & 72.0 \\
\hline $\begin{array}{l}\text { Specific fuel } \\
\text { consumption, } \\
\text { lbm/lbf-hr }\end{array}$ & 0.81 & 0.79 & 0.77 & 0.75 \\
\hline
\end{tabular}

(b) Cruise at Mach 2.4 at $60000 \mathrm{ft}$ (maximum dry)

\begin{tabular}{|c|c|c|c|c|}
\hline Airflow, $W_{a}, \mathrm{lbm} / \mathrm{sec}$ & 342 & 364 & 388 & 414 \\
\hline Fan pressure ratio & 2.62 & 2.44 & 2.26 & 2.09 \\
\hline $\begin{array}{c}\text { Core-driven-fan } \\
\text { pressure ratio }\end{array}$ & 1.19 & 1.19 & 1.19 & 1.19 \\
\hline $\begin{array}{l}\text { High-pressure- } \\
\text { compressor } \\
\text { pressure ratio }\end{array}$ & 3.55 & 3.82 & 4.14 & 4.47 \\
\hline $\begin{array}{l}\text { Overall pressure } \\
\text { ratio }\end{array}$ & 11.1 & 11.1 & 11.1 & 11.1 \\
\hline Bypass ratio: & & & & \\
\hline Inner & 0.66 & 0.66 & 0.66 & 0.66 \\
\hline Outer & 0.07 & 0.07 & 0.07 & 0.07 \\
\hline $\begin{array}{l}\text { Combustor exit } \\
\text { temperature, }{ }^{\circ} R\end{array}$ & 3560 & 3560 & 3560 & 3560 \\
\hline $\begin{array}{l}\text { Ratio of thrust to } \\
\text { airflow, } F_{n} / W_{a} \\
\text { lbf-sec/lbm }\end{array}$ & 48.9 & 45.1 & 41.3 & 37.9 \\
\hline $\begin{array}{l}\text { Specific fuel } \\
\text { consumption, } \\
\text { lbm/lbf-hr }\end{array}$ & 1.28 & 1.272 & 1.273 & 1.279 \\
\hline $\begin{array}{l}\text { Installed thrust, } \\
F_{n}, \text { lbf }\end{array}$ & 16726 & 16400 & 16017 & 15671 \\
\hline
\end{tabular}


TABLE II. - PROPULSION

SYSTEM WEIGHTS

\begin{tabular}{|c|c|}
\hline $\begin{array}{c}\text { High-pressure } \\
\text { compressor } \\
\text { bleed, } \\
\text { percent }\end{array}$ & $\begin{array}{c}\text { Engine } \\
\text { pod } \\
\text { weight, } \\
\text { lbm }\end{array}$ \\
\hline 2 & 14739 \\
10 & 15802 \\
17.5 (base) & 16534 \\
24 & 17671 \\
\hline
\end{tabular}

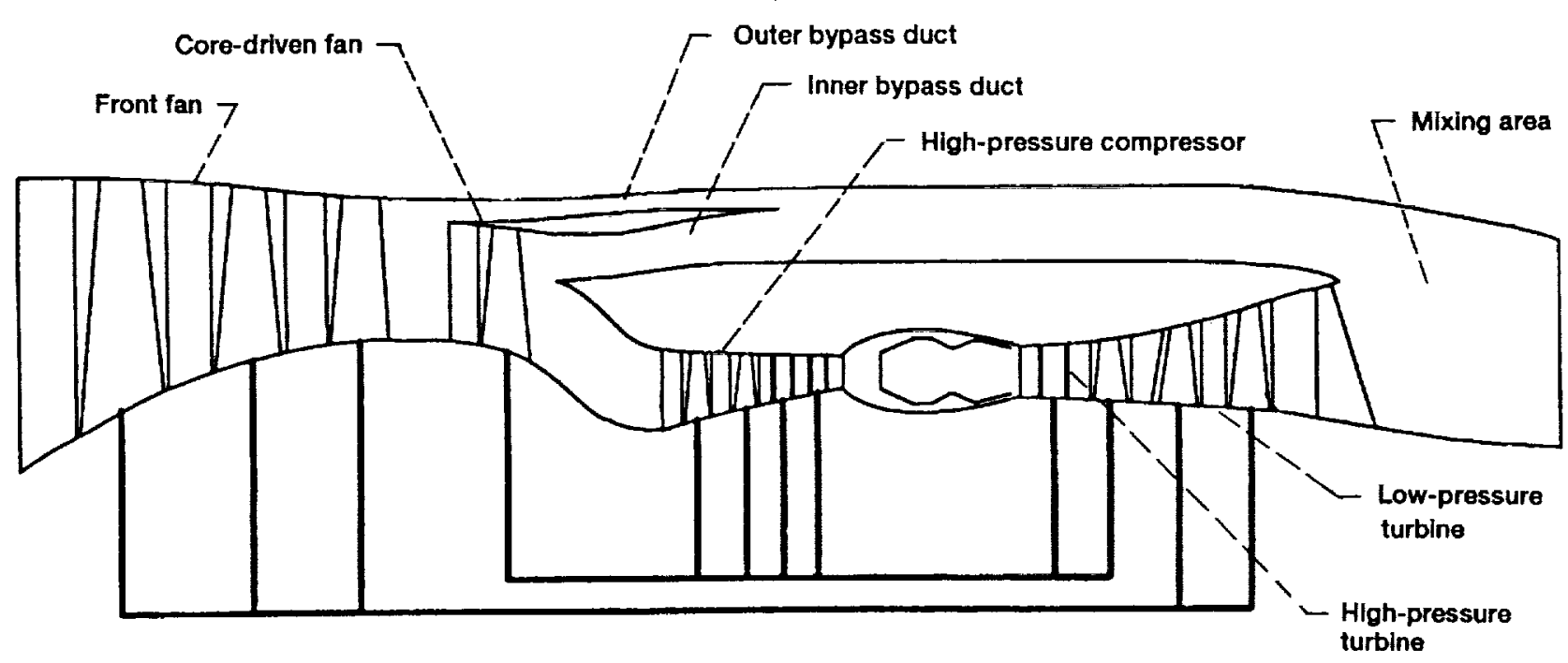

Figure 1.-Variable-cycle engine.

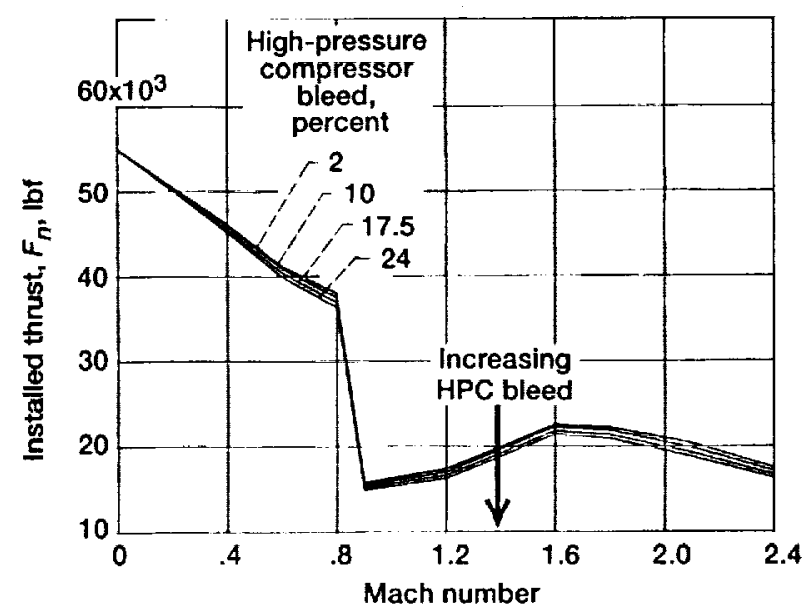

Figure 2.-Installed thrust of study engines along flightpath before mission sizing.

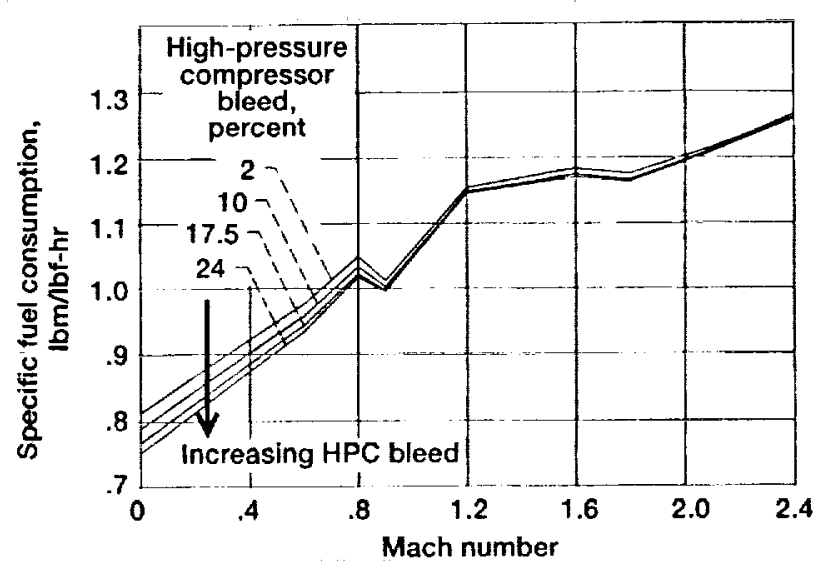

Figure 3.-Specific fuel consumption during mission. 


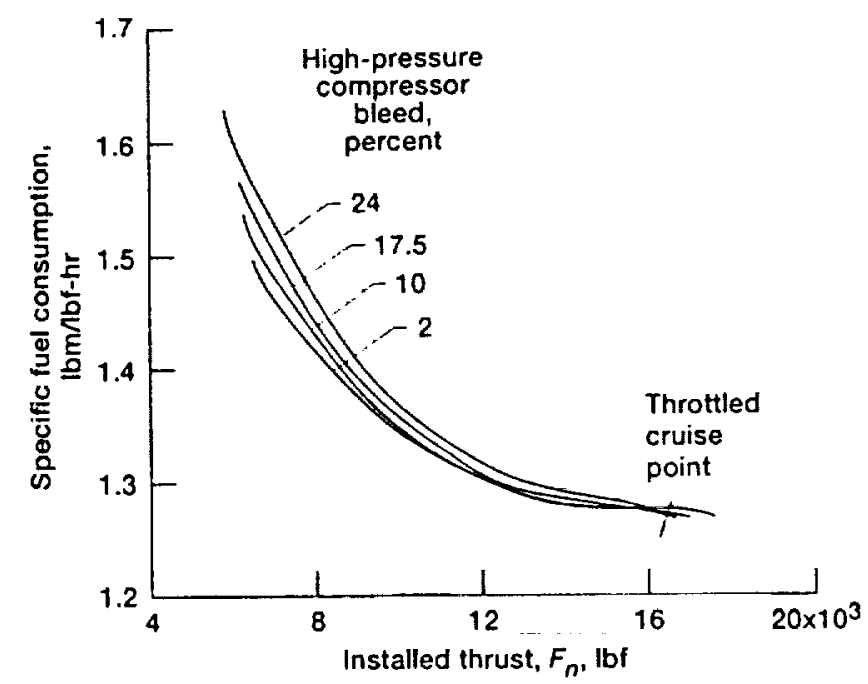

Figure 4.-Study engine throttle curves (Mach 2.4 at $60000 \mathrm{ft}$ ).

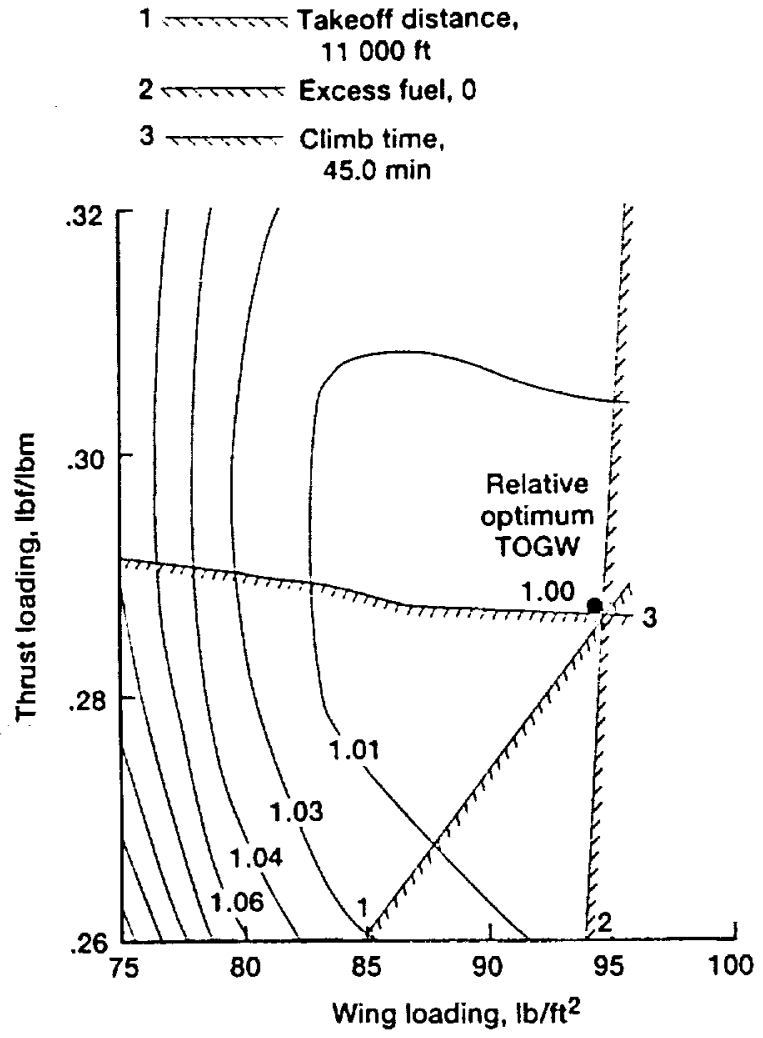

Figure 5.-Aircraft sizing thumbprint. Variable-cycle engine; all dry; high-pressure compressor cooling, 17.5 percent; takeoff gross weight (TOGW), 1.0 to 1.10.

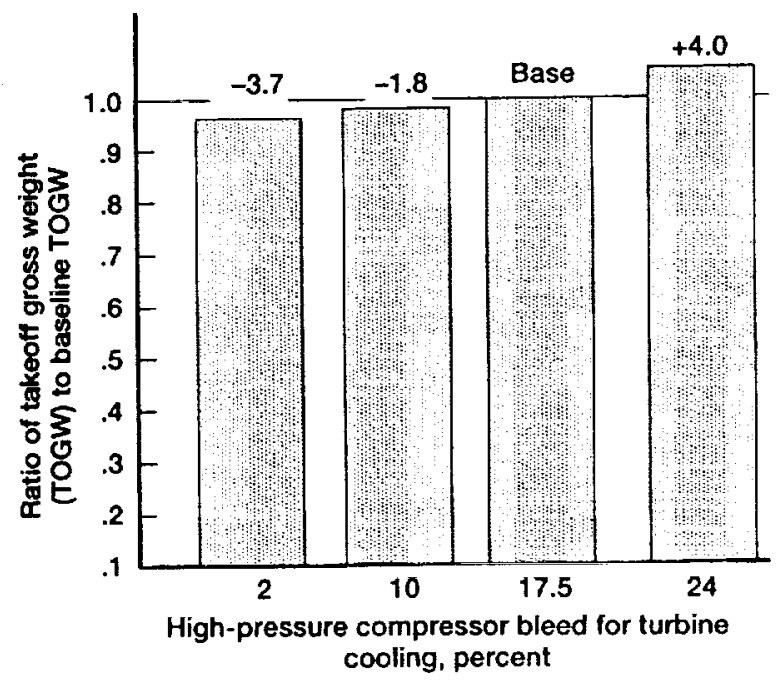

Figure 6.-Effects of study engines on aircraft takeoff gross weight. 
Public reporting burden for this collection of information is estimated to average 1 hour per response, including the time for reviewing instructions, searching existing dala sources, gathering and maintaining the data needed, and completing and reviewing the collection of information. Send comments regarding this burden estimate or any other aspect of this collection of information, including suggestions for reducing this burden, to Washinglon Headquarters Services, Directorate for information Operations and Reports, 1215 Jefferson Davis Highway, Suite 1204, Arlington, VA 22202-4302, and to the Office of Management and Budget, Paperwork Reduction Project (0704-0188), Washington, DC 20503.

\begin{tabular}{|l|l|l} 
1. AGENCY USE ONLY (Leave blank) & 2. REPORT DATE & 3. REPORT TYPE AND DATES COVERED
\end{tabular}

4. TITLE AND SUBTITLE

May 1992

Technical Memorandum

Effects of Turbine Cooling Assumptions on Performance and Sizing of

High-Speed Civil Transport

6. AUTHOR(S)

Paul F. Senick

WU-537-01-22

5. FUNDING NUMBERS

7. PERFORMING ORGANIZATION NAME(S) AND ADDRESS(ES)

8. PERFORMING ORGANIZATION REPORT NUMBER

National Aeronautics and Space Administration

Lewis Research Center

Cleveland, Ohio 44135-3191

E-6948

9. SPONSORING/MONITORING AGENCY NAMES(S) AND ADDRESS(ES)

10. SPONSORING/MONITORING AGENCY REPORT NUMBER

National Aeronautics and Space Administration

Washington, D.C. 20546-0001

NASA TM -105610

11. SUPPLEMENTARY NOTES

Responsible person, Paul F. Senick, (216) 433-7024.

12a. DISTRIBUTION/AVAILABILITY STATEMENT

12b. DISTRIBUTION CODE

Unclassified - Unlimited

Subject Category 07

13. ABSTRACT (Maximum 200 words)

The analytical study presented herein examines the effects of varying turbine cooling assumptions on the performance of a High-Speed Civil Transport propulsion system as well as the sizing sensitivity of this aircraft to these performance variations. The propulsion concept employed in this study was a two-spool, variable-cycle engine with a sea-level thrust of $55000 \mathrm{lbf}$. It is one of several promising cycles being considered to power the High-Speed Civil Transport within the High-Speed Research Program. The aircraft used for this study was a representative 250-passenger vehicle with a cruise Mach number of 2.4 and $5000-\mathrm{n}$ mi range. The differences in turbine cooling assumptions were represented by varying the amount of high-pressure compressor bleed air ( 2 percent for fuel-cooled or ceramic turbines to 24 percent for current turbine materials) used to cool the turbines. It was found that as this cooling amount was increased, the engine size and weight increased but specific fuel consumption (at takeoff and climb) decreased. However, all study engines had approximately the same cruise value of specific fuel consumption. Because most of the mission is spent at cruise, the specific fuel consumption advantage of the higher bleed engines scen during subsonic flight was minimized and the lower bleed, lighter weight engines led to the lowest takeoff-gross-weight vehicles. Finally, the change in aircraft takeoff gross weight versus turbine cooling level is prescnted.

14. SUBJECT TERMS
High speed; Variable cycle engine (VCE); Propulsion; Turbine blades; Turbines; Propul-
sion system performance; Aircraft performance; Weight analysis

17. SECURITY CLASSIFICATION OF REPORT

Unclassified

18. SECURITY CLASSIFICATION
OF THIS PAGE
Unclassified

Unclassified

\section{SECURTYY CLASSIFICATION OF ABSTRACT Unclassified}

15. NUMBER OF PAGES

16. PRICE CODE

$\mathrm{A} 03$

20. LIMITATION OF ABSTRACT

Standard Form 298 (Rev. 2-89) Prescribed by ANSI Std. Z39-18 298-102 